\title{
Neighbors Connected; Exploring Recruitment of Dutch Older People for Activities
}

\author{
Jeanette Lezwijn ${ }^{1,2}$, Lenneke Vaandrager ${ }^{2}$, Annemarie Wagemakers ${ }^{2}$, Maria Koelen ${ }^{2}$, \& Cees van Woerkum ${ }^{3}$ \\ ${ }^{1}$ GGD Noord- en Oost-Gelderland (Community Health Service), AGORA Academic Collaborative Centre, Apeldoorn, \\ The Netherlands \\ ${ }^{2}$ Wageningen UR, Department of Social Sciences, Health and Society, Wageningen, The Netherlands \\ ${ }^{3}$ Wageningen UR, Department of Social Sciences, Communication and Innovation Studies, Wageningen, The \\ Netherlands \\ Correspondence: Jeanette Lezwijn, GGD Noord- en Oost Gelderland, PO Box 51, 7300 AB Apeldoorn, The \\ Netherlands. E-mail: J.Lezwijn@ggdnog.nl
}

Received: May 7, 2015

Accepted: May 22, $2015 \quad$ Available online: June 8, 2015

doi: $10.11114 /$ ijsss.v3i4.856

URL: http://dx.doi.org/10.11114/ijsss.v3i4.856

\begin{abstract}
The recruitment of older people to engage in actions aimed at promoting health is an issue that does not receive much attention within health promotion practice. Many activities for older people are organized; however, less socially active older people do not participate in such activities. The aim of this study is to examine how to successfully recruit less socially active older people to participate in social activities. By means of a short questionnaire completed by 254 participants, and interviews with 12 participants and 9 organizers, we identified four elements that facilitate recruitment of less socially active older people to participate in social activities of the programme Neighbours Connected. These elements are: (i) personal contact with organizers, (ii) social support, (iii) close proximity and easy accessibility, and (iv) an opportunity offered by the activity itself for social interaction and for learning new things. These elements contribute to perceiving activities as comprehensible, manageable, and meaningful. We conclude that the elements that improve recruitment for activities mainly relate to the context in which the activity is organized, rather than to the content of the activity. For future programmes this means that in recruitment, focus should be as much on the context in which an activity takes place as on the content of the activity.
\end{abstract}

Keywords: health promotion, older people, salutogenesis, sense of coherence, qualitative methods

\section{Introduction}

Healthy ageing is defined as "the process of slowing down, physically and cognitively, while resiliently adapting and compensating in order to optimally function and participate in all areas of one's life (physical, cognitive, social and spiritual)" (Hansen-Kyle, 2005: 52). This definition stresses the different needs of individuals while adapting and compensating changes. Besides, healthy ageing, just as health, is influenced by a variety of interacting determinants (World Health Organization [WHO], 2002), such as individual lifestyle factors, social and community networks, living and working conditions, and general socioeconomic, cultural, and environmental factors (Dahlgren \& Whitehead, 2006). An important determinant of healthy ageing is social participation (Croezen, Haveman-Nies, Alvarado, Van't Veer \& De Groot, 2009; Naaldenberg, Vaandrager, Koelen, \& Leeuwis, 2011; Richard, Gauvin, Gosselin, \& Laforest, 2009; Utz, Carr, Nesse, \& Wortman, 2002), which is defined as social interaction with persons other than one's spouse (Utz et al., 2002).

One form of social participation is taking part in activities that create opportunities for meeting other people (Bath \& Deeg, 2005). Meeting people is needed to build social relationships. In municipalities in the Netherlands, all kind of activities are being organized, for example by welfare work, where older people can meet each other. However, less socially active older people often do not take part in such activities. Local organizations do not know how to recruit this group (Lezwijn, Vaandrager, Naaldenberg, Wagemakers, Koelen, \& Van Woerkum, 2011a).

This study is not about the impact that participation in social activities has on health or a determinant of health, as studied by many others (e.g. Bath \& Deeg, 2005); rather, it aims to examine how to successfully recruit less socially 
active older people to participate in social activities, as this is a key factor in promoting social participation. For this purpose the Dutch programme 'Neighbours Connected' is examined. Neighbours Connected is a community based programme in which socially active older people are supported to organize activities for their less socially active older neighbours.

The article is structured in four sections. First, we elaborate upon the HP2.0 framework and the development of Neighbours Connected, the methods of data collection and the analytical framework of this study. Second, we present our findings. Next, we discuss the results, and some considerations concerning the research. Finally, we give the main conclusions from this study.

\section{The HP 2.0 framework}

Neighbours Connected has been developed by means of the HP 2.0 framework (Lezwijn et al., 2011a) and a participatory approach, based on the principles of health promotion (Rootman et al, 2001). The HP 2.0 framework (Figure 1) is based on salutogenesis, which is a perspective that focuses on the causes of health rather than on the causes of disease (pathogenesis) (Antonovsky, 1987, 1996; Ciairano, Rabaglietti, Martini, \& Giletta, 2008; Eriksson \& Lindström, 2008; Lindström, 2005, 2006; Lindström \& Eriksson, 2010).

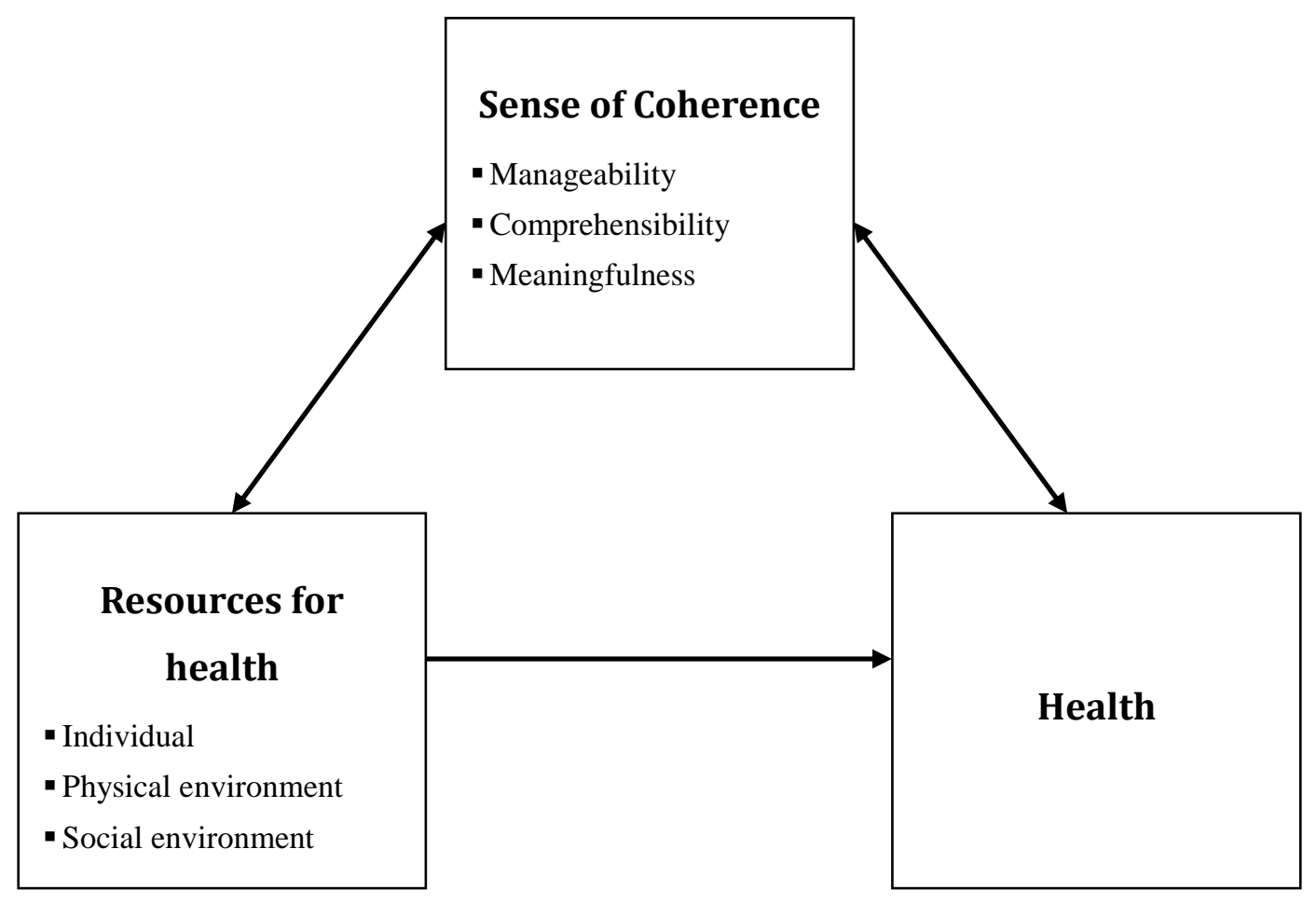

Figure 1. HP 2.0 framework (Lezwijn et al., 2011a: 46)

The HP 2.0 framework is meant to support the development (including recruitment), implementation and evaluation of health promotion activities for healthy ageing. It is built upon three interrelated central concepts: (1) sense of coherence (SOC), (2) resources for health, and (3) health. The framework visualises the interrelationships of these three concepts.

The SOC is a feeling of confidence that one is able to make use of resources in a way that positively influences health and wellbeing (Antonovsky, 1987, 1996; Eriksson \& Lindström, 2008; Lindström, 2005, 2006). The resources for health are resources which can be used in order to be in control of situations affecting people's lives and can be found in the person self and in the social and physical environment. Individual resources for health are for instance knowledge, education level and experience. Examples of environmental resources are shopping facilities, neighbours, activities being organized and health services.

The SOC exists out of three dimensions; comprehensibility, manageability and meaningfulness. We expect that these dimensions of SOC influences recruitment of less socially active older people to participate in social activities. Related to the recruitment for social activities, comprehensibility reflects a person's perception that the information he/she is getting about an activity is structured and explicable. One is able to judge whether one wants to participate. Manageability reflects a person's perception of his/her resources, especially related to his/her ability to use them 
effectively, including his/her own capabilities to participate in the activity. Meaningfulness reflects a person's perception about whether or not the activity will give meaning to him or her at an emotional level (Antonovsky, 1996; Ciairano et al., 2008; Lindström, 2005).

The HP 2.0 framework indicates that successful recruitment depends on whether the social activities are meeting the SOC of potential participants. If they are adapted to the SOC of these potential participants it can facilitate participation.

Using SOC within health promotion research is not new. SOC is already frequently used as an outcome of health promotion strategies (i.e. Bauer, Davies, \& Pelikan, 2006; Eriksson \& Lindström, 2008; Langeland \& Wahl, 2009; Lindström \& Eriksson, 2009; Wainwright et al., 2007). However, in this study, SOC is used to study elements of social activities that make elderly people perceive them as comprehensible, manageable and meaningful. As far as we know, SOC has not been used before in this way.

\section{Development of Neighbours Connected}

Researchers, local professionals, policymakers and older people were involved in developing Neighbours Connected. To consider what kinds of action was needed to improve healthy ageing within a municipality, different studies were conducted. These studies were: i) interviews with local stakeholders and older people (Naaldenberg, Vaandrager, Koelen, \& Leeuwis, 2011; Lezwijn Naaldenberg, Vaandrager, \& Van Woerkum, 2011b), ii) local epidemiological data (Croezen, 2010; Croezen et al., 2009), and iii) interactive sessions with policy makers, local stakeholders, and older people to discuss the results from the interviews and the epidemiological analyses (Lezwijn et al., 2011b). The outcomes of these different studies, revealed the following criteria for action: 1) a positive approach to healthy ageing, 2) a supportive environment in which neighbours play an important role, 3) clear communication and visibility of activities, and 4) the active involvement of older people in their own situation (Lezwijn et al., 2011b).

The literature shows that neighbours and a neighbourhood, where older people are satisfied and where they feel at ease, can contribute to healthy ageing (Bowling \& Gabriel, 2007; Croezen, 2010; Mohnen, Groenewegen, Völker, \& Flap 2011; Naaldenberg et al., 2011). Neighbours are more familiar with the context in which less socially active older people live, such as living circumstances, physical and/or mental limitations, and their contact with neighbours, because it is partly their context as well (Laverack, 2009).

Neighbours Connected is therefore a community-based programme supporting socially active older people (hereafter formulated as the organizers) to organize activities for people in their neighbourhood whom they consider less socially active older neighbours (hereafter formulated as the participants). The organizers are facilitated by Neighbours Connected by means of practical support, such as printing leaflets, writing press releases, and arranging a location for the activity, and financial support up to a maximum of $€ 500$ (Lezwijn et al., 2011b). Furthermore, the Neighbours Connected project worker and the organizer of the activity regularly discuss the activity, the planning, and the methods to reach possible participants.

In the period May 2009 to May 2010 different kinds of activities were organized. Some examples include: a course to make Christmas cards, an afternoon in the village with sketches and music in the local dialect, an afternoon in a village playing bingo with music and song, and one-day excursions. The activities were divided into three categories, namely 1) creative courses, 2) excursions and 3) nice afternoons nearby (Table 1).

Table 1. Breakdown of the activities of Neighbours Connected

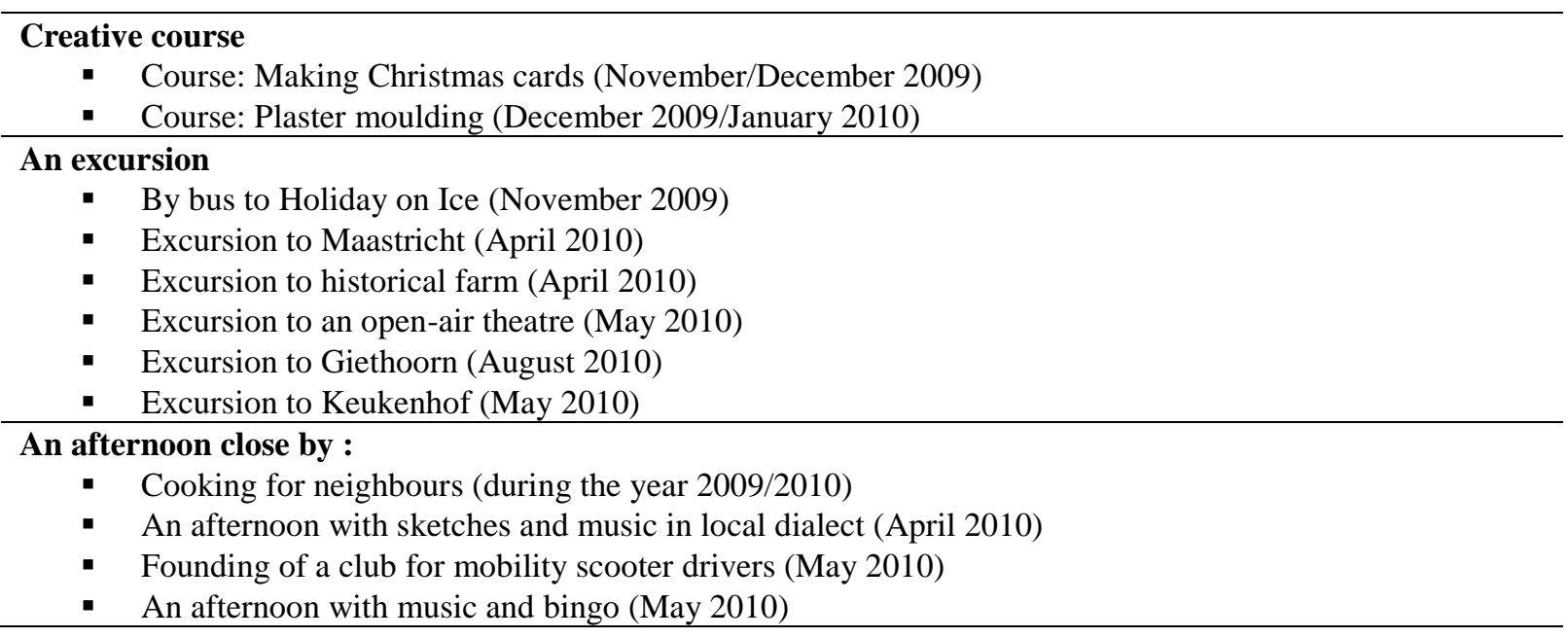




\section{Methods}

To explore the successful recruitment elements of social activities a multiple methods approach was used: 1) a short questionnaire with open questions among the participants, 2) in-depth interviews with participants, and 3) interviews with the organizers of the activities. Using multiple methods is an important verification technique to improve the reliability of the results (Cohen \& Crabtree, 2008; Koelen, Vaandrager, \& Colomer, 2001; Silverman, 2006).

\subsection{Short Questionnaire Completed By Participants In Activities}

The participants filled in a short questionnaire directly after the activity $(\mathrm{N}=254)$. The short questionnaire consisted of three open-ended questions about how they became aware of the activity, what they thought about the activity, and whether there was any likelihood that they would participate again if the opportunity arose. Next to these questions the participants rated their health on a five-point scale of 1 to 5 ( 5 being the best score).

\subsection{Interviews with Participants}

The first author phoned 22 participants who had indicated on the short questionnaire that they were willing to participate in an in-depth interview. From all activities, participants were randomly selected. After twelve in-depth interviews no new insights appeared. The year of birth of interviewed participants ranged from 1923 to 1944 . All interviewed participants were women, who positively judged their health (average of 4,3 points) and they were all positive about the activities in which they participated. Reasons not to participate in the interview (10 respondents) included: feeling too old, feeling unable to share their thoughts and experiences, and being too busy. Four of the interviewed participants were from a creative course, three from an afternoon close by, and five from an excursion. The interviews took place at the homes of the participants, were approximately 30-45 minutes in length, and were audio-taped and transcribed verbatim for analysis by an external bureau. The interview contained open questions which were based upon the 3-item scale of the Life Orientation Questionnaire. The Life Orientation Questionnaire is a scale, frequently used to measure SOC (Antonovski, 1996; Wainwright et al., 2007). Examples of interview questions are: "What attracted you in the announcement of the activity that made you to decide to participate?" and "What are important factors for you to be able to participate?"

\subsection{Interviews with Organizers}

The first author conducted nine interviews with organizers of the twelve activities, the so-called socially active older people, 6 women and 3 men. Organizers of three activities were not interviewed because all categories of activities were represented well and no new information was expected. These interviews probed what the organizers thought about Neighbours Connected and why and how they organized the activity within Neighbours Connected. The interviews took place at the homes of the interviewees, were approximately 60-75 minutes in length, and were audio-taped and transcribed verbatim for analysis by an external bureau. From these interviews, it was possible to create an understanding of the successful recruiting elements of social activities and in what way they are comprehensible, manageable, and meaningful for the participants.

\subsection{Analysis}

The interviews with participants and organizers were analysed as a total group of 21 interviews using the qualitative analysis software ATLAS ti 5.0 (Science Software Development), which fosters transparency during the analytical process. The data were analysed using a combination of a top-down and a bottom-up approach (Silverman, 2006; Coffey \& Atkinson, 1996) (Figure 2).

In the top-down approach of the analysis, three pre-defined codes, namely comprehensibility, manageability, and meaningfulness, were used to assign fragments of the transcripts. To assign fragments to the pre-defined codes, the 29-item Life Orientation Questionnaire was used to support the coding process. In the bottom-up approach, the data from the quotations of participants about comprehensibility, manageability, and meaningfulness were freely coded into several elements such as "pleasant" and "together". This process provided 180 elements and 1,062 quotations partly divided between the three dimensions of SOC. A bottom-up approach in analyses of interviews with organizers, was not appropriate, because of the small number of quotations within the pre-defined codes. 


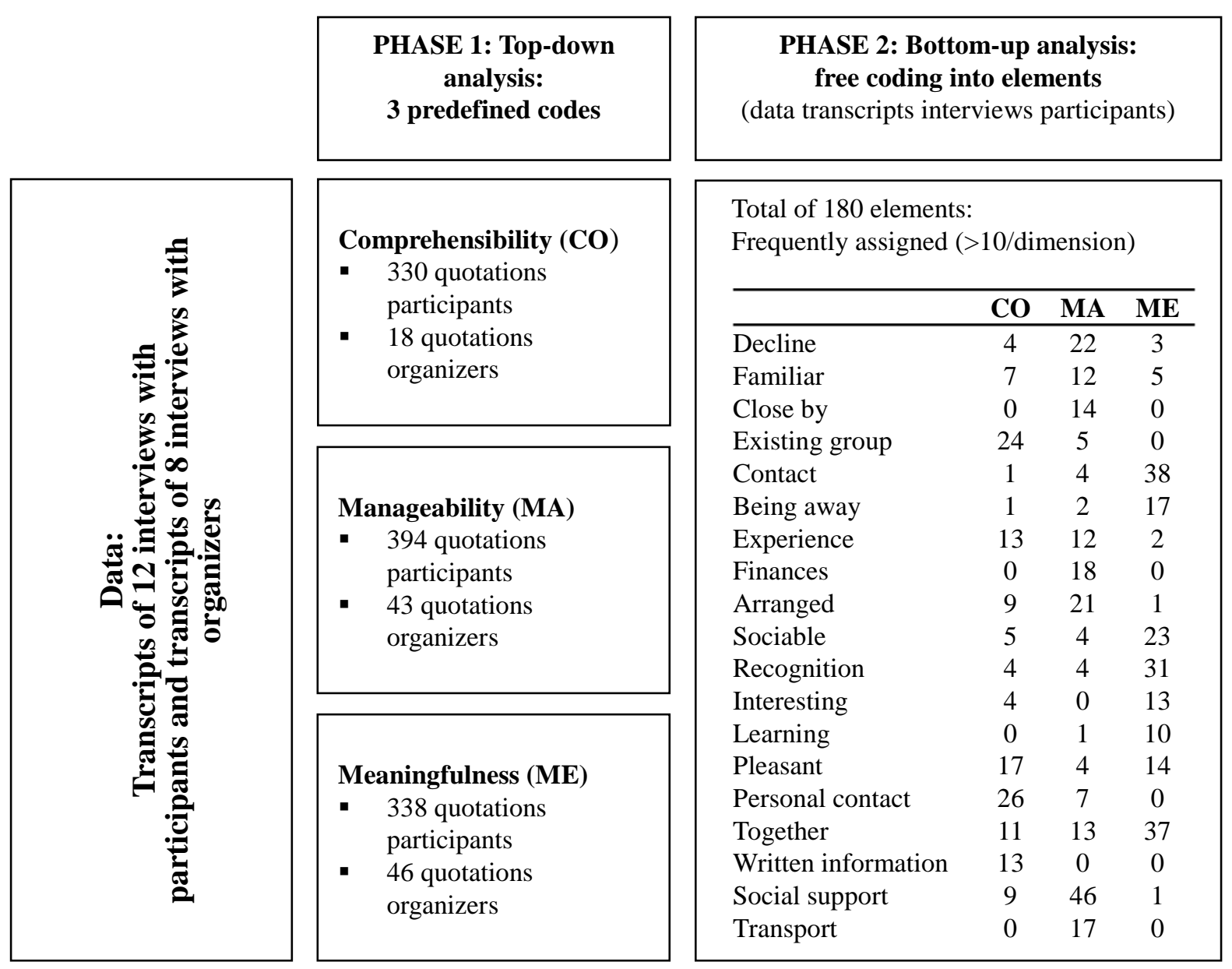

Figure 2: Analysis of interviews with Participants and Organizers of activities

\subsection{Interpretation of Data}

The data from the 12 participant interviews about the recruitment and the appreciation of the current activities and about the visioning of important aspects of future activities revealed elements that contribute to the comprehensibility, manageability, and meaningfulness of activities. Some of these elements are characteristics of the older people themselves, such as experience and physical or mental decline. We focus on the elements that are characteristic for the activity itself. Those elements are, consciously or not, added by the organizers. The data from the 254 short questionnaires serve as a check of the first findings from the participant data. The data from the interviews with nine organizers was used to assess whether and how organizers deal with issues - deemed important by participants concerning the comprehensibility, manageability, and meaningfulness of activities. The quotations in the results section have been selected by the first three authors, on basis of frequently assigned codes (see Figure 2) and on basis of how they best exemplify how people talk about the elements related to the activities.

\section{Results}

Results of the interviews with participants and organisers are reported together; the content of the data mainly concerned elements supporting the recruitment of socially active older people. They are presented in line with the dimensions of comprehensibility, manageability and meaningfulness.

\subsection{Elements Supporting Comprehensibility}

Two elements of an activity that make participants perceive it as comprehensible are: 1) personal contact and 2) written information. First, personal contact between the organizers and older people helps the participants to perceive the activity as comprehensible. Personal contact may be necessary to convince people that the activity is meant for them as well. It can take place in an existing group where the majority of the people already know each other, such as a weekly coffee morning at Elderly Welfare or the monthly evenings of the women associates. Within such groups, it is possible to ask the organizers questions and the organizers can distribute information about the activity. Another form of personal contact is when someone is asked by a neighbour, or another familiar person, to join the activity. In such cases, 
participants get personal information and felt more able to judge if he or she wanted to participate as well. Data from the short questionnaires confirm the importance of personal contact, because the majority replied that personal contact with, for example, neighbours, but also with organizers, convinced them to go.

Second, written information, such as leaflets and newspapers is needed; however, it should always complement personal contact to attract people to the activity and to show that the activity could be nice for them as well. Written information should always provide clear information about the programme, date, place, and time, without using difficult words, as following quotation of a participant shows:

...and sometimes people read the newspaper and then you think "what do they mean by that?" That is everywhere and we have not learned those difficult words at school.

Written information is necessary to remember the activity and to talk about it with family, neighbours, or acquaintances. Furthermore, when written information about the activity is offered in several ways, such as in local newspapers, in leaflets, and via an organization or acquaintances, this increases the chance of participants actually seeing and noticing the activity. However, as one of the organizers experienced, without personal contact and with only articles in local newspapers, people are not attracted to the activity.

\subsection{Elements Supporting Manageability}

Important elements to ensure that participants perceive the activity as manageable are: 1) an accessible location close by, 2) arranged transport, and 3) experiencing social support. First, an accessible location close by, especially for older people with some limitations, is a positive prerequisite to participate, as following quotation of a participant shows:

Those things I find important. If I have to go to the other side of the city, then I say no. If I can just cross the street, then that's pleasant for me. And if I want to, I can go home again.

Second, a practical issue such as arranged transport takes the manageability dimension of participants into account, as was the case with the excursions. The older people found this very easy.

Interviewer (I): You were picked up by your niece to get on the bus? Participant (P): Yes, and the bus also brought us back home again. That was lovely and afterwards you had a good feeling. That is what I experienced.

Third, the most important issue for manageability is when participants experienced social support from neighbours, friends, or family. Participants enjoy going together to an activity. In such cases, participants experience mutual support to actually participate. Within one activity, the organizers were very conscious of the social support that older people needed to participate. The organizers themselves were very active in organizing this social support, as following quotation of one of the organizers illustrates:

\section{I called the man and I said "take your brother as well."}

The social support of the organizers themselves can also be very helpful when people arrive alone for the first time at an activity. One woman's experience was that you should sometimes help people to cross the threshold. One way of doing this, is to offer coffee or tea and to talk with them.

\subsection{Elements Supporting Meaningfulness}

The following two elements contribute to meaningfulness: 1) the content of the activity should, according to participants, be interesting, new, or pleasant, and 2) the activity should create opportunities to meet other people. First, the participants take part in activities that they find interesting, that are new to them, and that they perceive as pleasant. Older people find meaning in activities in which they can learn. This was especially seen in the creative courses and during the excursions. As this older woman finds:

I: And for the next time, what would especially be meaningful for you to participate in such activity again? P: Yes, especially the people and you can hear of other things. Yes, you can learn something about it.

Second, and according to the participants more important, is that when they actually participate, they also meet other people. In some cases, these people are new people, but in other cases they are neighbours from the past, with whom they have a shared history. Life stories from the past, but also from the present, sometimes have similarities with their own, and they recognize themselves in those stories; this is highly appreciated.

For example this week we had something, "O gosh, yes I have forgot that". "Oh, do you have the same?" "O yes, everyone forget things so now and then”. And you think you are the only one who is forgetful.'

Organizers realize that doing things together is important for participants. Therefore, within all organized activities, meeting other people and doing things together is an important part. As one of the organizers said about her course: 
I don't do the course to make cards. I do the course for the sociability, for those people.

The data gathered by the short questionnaire also showed that the sociability of the activity and being together were seen as main success factors.

\subsection{Elements Supporting More Than one Dimension}

In the bottom-up part of the analyses of 12 interviews with participants, some elements of an activity support more than one dimension of SOC or can even be seen as elements which go beyond the three categories. These elements are: "pleasant" and "together." The first element, pleasant, means that, when participants perceive an activity as nice or good, they also perceive the activity as more comprehensible and meaningful. In such cases, the participant notices the activity more easily than when an activity is not perceived as nice. Furthermore, participants understand the content of the activity in advance and therefore they can more easily judge if the activity is meant for them as well (comprehensibility). And pleasant activities are, according to the respondents, meaningful activities. The participant can have some prior experience with similar activities or be familiar with positive stories about similar activities. An activity that is perceived as pleasant will increase the chance of someone participating in the activity. Because when the activity is seen as comprehensible and meaningful, then there will be a strong motivation to make use of the resources (Antonovsky, 1996) to actually participate. The second element, "together", contributes to comprehensibility, manageability, and meaningfulness. This means that discussing the information and the activity with others, and having an opportunity to decide with others whether to participate or not, contributes to comprehensibility. The activity is perceived as manageable when the participants perceive mutual support when they go together. It seems easier to overcome possible barriers, doing it together. And the activity is perceived as meaningful, because older people find meaning in doing things together, and this contributes to building and sustaining social relationships as well.

\section{Discussion}

Many activities for older people are organized in municipalities; however, less socially active older people do not participate in such activities. In this study we found a number of elements which facilitate recruitment of less social active elderly. These elements relate to the comprehensibility, manageability and meaningfulness of activities and how the activities meet the SOC of potential participants or not. This is an innovative approach, since these concepts are used for the recruitment of activities, rather than as an outcome of a health promotion strategy. In this study the focus was limited to the SOC components only. For further research it would be interesting to study resources and health as well, the two other parts of the HP 2.0 framework.

The findings from the multi-method approach show that, although the physical and mental condition of the older people themselves seem to be an important issue in whether they will take part in activities or not (Bowling \& Gabriel, 2007), some elements of activities itself can influence recruitment as well. These elements are: (i) personal contact with organizers, (ii) social support in the decision phase about participating and the phase of actually going to the activity, (iii) close proximity and easy accessibility of the location of the activity, and (iv) an opportunity offered by the activity itself for social interaction and for learning new things. These elements improve the chance of less socially active older people taking part in the activity and will therefore probably enhance social participation.

Interestingly, the four elements focus mainly on the question of how the activity is organized, namely, the circumstances in which the activity takes place and the opportunities for social interaction, rather than on the content of the activity. Especially creating opportunities for social contact and social support prior to and during the activities seem to be essential for the perception that activities are comprehensible, manageable, and meaningful. A possible reason for this is that social contact with similar others contributes to self-identity (Sheldon \& Burke, 2000; Utz et al., 2002), and perceiving support from familiar social contacts helps people to decide to go. Thereby, participants feel more comfortable going together to an activity than going alone; this was also found by Naaldenberg et al., (2011). When people have to be convinced about the question of whether this activity is also meant for them (comprehensibility), or to cross the threshold (manageability), personal contact or social support is needed from the organizers of the activity. In these cases, the organizers fulfil the role of similar experts (Suls, Martin, \& Wheeler, 2002), who are people with some similarities to potential participants, but who are more knowledgeable concerning the activity. In Neighbours Connected, the organizers belong to the older population from the same neighbourhood or village. When participants compare themselves with the organizers contributes to acknowledging that the activity is meant for oneself as well (Suls et al., 2002).

The location, which makes an activity more manageable, contributes to perceiving control of the situation. People can come more easily, but can also decide to leave the activity. To a lesser extent than social contact, learning or hearing new things is also important for older people to find meaning in the activity. What people find interesting to learn relates to their identity (Krause, 2004). 
Neighbours Connected has been developed because of difficulties experienced by local organizations with the recruitment of less socially active older people for activities in municipalities. This is a very relevant subject, because when one is not able to recruit people to participate in an activity, the activity is not effective. Neighbours Connected is an innovative approach within the field of healthy ageing because the focus of Neighbours Connected is not on the content of the activity, but rather on the process of organizing, and on the circumstances in which activities are organized. There are some similar projects (Bobbitt-Cooke, 2005; Foster-Fishman et al., 2006; Hartwig et al., 2006; Schmidt, Plochg, Harting, Klazinga, \& Stronks, 2009; Tan et al., 2010) however, within these programmes the combination of financial and practical support was not available for older people organizing an activity for their neighbours, only for organizations. Providing financial and practical support to the organizers, as was done by Neighbours Connected, improved the opportunities to actually organize the activity for their older neighbours.

Four considerations concern the recruitment of participants for the interviews. All participants were women since the recruitment took place through activities in which mainly women participated. An explanation might be that activities are more appealing to women and that older women are more often widowed compared to men. This implies that these results cannot be generalized to men and that further research is necessary to conclude if the approach of Neighbours Connected is suitable for the recruitment of older men as well. Furthermore, whether these respondents were actually "less socially active" was based on the perception of organizers and not measured. Some participants of activities were not willing to participate in the interviews, because they felt they were too old and felt were not able to share their thoughts and experiences with the interviewer. Thoughts which could also inhibit them to participate at activities. However, the non-respondents did participate in activities organized by their neighbours. So, within this inquiry more attention for recruiting the older people to participate in our interviews, would have been beneficial for the research. It also illustrates that similarities can be found between recruiting certain groups of older people for participating in activities and recruiting the same groups of older people for participating in research. Another limitation concerns the fact that the SOC was used as the lens to create and understand the data which detracts that other components could also have influenced the recruitment. Finally, a limitation of this study may be its relatively small sample size. This is mitigated by the fact that elements became repetitive (such as the importance of personal contact, social support and being together), where it was concluded that data saturation may have been reached.

\section{Conclusion}

Neighbours Connected aims to improve the recruitment of less socially active older people by offering them comprehensible, manageable, and meaningful activities. For this, four elements to improve recruitment to the activities are formulated, so that barriers to participate at the activity are removed. These elements are: (i) personal contact with organizers, (ii) social support in the decision phase about participating and the phase of actually going to the activity, (iii) close proximity and easy accessibility of the location of the activity, and (iv) an opportunity offered by the activity itself for social interaction and for learning new things. By adapting social activities to older people's SOC, the relationship within the HP 2.0 framework between SOC and resources for health - also called the salutogenic relationship (Eriksson \& Lindström, 2008; Lindström, 2005) - will be improved.

Using salutogenesis, and specifically the SOC concept, in the examination of the activities of Neighbours Connected led us to conclude that, for older people, the environment and the context in which activities are organized are important elements for recruitment. However, in health promotion practice, activities are often organized around a specific health theme. The context in which the activity takes place and how the activity is organized often receive limited attention during organizing the activity as well as within the evaluation of the activity. In our view, SOC and the three dimensions of SOC are useful concepts within health promotion practice to improve the recruitment, so that more less socially active older people will participate.

\section{Acknowledgement}

This work was supported by The Netherlands Organization for Health Research and Development ZonMw (project number 50-50400-98-008).

This study is part of the healthy ageing project of Academic Collaborative Centre AGORA. The authors wish to thank all interviewees for their time.

\section{References}

Antonovsky, A. (1987). Unraveling the mystery of health. San Francisco: Jossey-Bass.

Antonovsky, A. (1996). The salutogenic model as a theory to guide health promotion. Health Promotion International, 11, 11-18. http://dx.doi.org/10.1093/heapro/11.1.11

Bath, P.A. \& Deeg, D. (2005). Social engagement and health outcomes among older people: Introduction to a special section. European Journal of Ageing, 2(1). 24 - 30. http://dx.doi.org/10.1007/s10433-005-0019-4 
Bauer, G., Davies, J.K, Pelikan, J., \& on behalf of the Euphid Theory Working Group and the Euphid Consortium. (2006). The EUHPID Health Development Model for the classification of public health indicators. Health Promotion International, 21, 153-159. http://dx.doi.org/10.1093/heapro/dak002

Bobbitt-Cooke, M. (2005). Energizing community health improvement: The promise of micro grants. Prevention Chronic Disease, Public Health Research, Practice and Policy, 2, 1-7. Retrieved from http://www.ncbi.nlm.nih.gov/pmc/articles/PMC1459464/

Bowling, A., \& Gabriel, Z. (2007). Lay theories of quality of life in older age. Ageing \& Society, 27, 827-848. http://dx.doi.org/10.1017/S0144686X07006423

Ciairano, S., Rabaglietti, E., Martini, R. D., \& Giletta, M. (2008). Older people's sense of coherence: Relationships with education, former occupation and living arrangements. Ageing \& Society, 28, 1075-1091. http://dx.doi.org/10.1017/S0144686X08007411

Coffey, A. \& Atkinson P. (1996). Making sense of qualitative data. Sage Publications Inc., California.

Cohen, D. J., \& Crabtree, B. F. (2008). Evaluative criteria for qualitative research in health care: Controversies and recommendations. Annals of Family Medicine, 6, 331-339. http://dx.doi.org/10.1370/afm.818

Croezen, S. (2010). Social relationships and healthy ageing. Epidemiological evidence for the development of a local intervention programme. Wageningen: Wageningen University.

Croezen, S., Haveman-Nies, A., Alvarado, V., Van't Veer, P., \& De Groot, C. (2009). Characterization of different groups of elderly according to social engagement activity patterns. The Journal of Nutrition, Health \& Aging, 13, 776-781. http://dx.doi.org/10.1007/s12603-009-0213-8

Crombie, I. K., Irvine, L., Williams, B., McGinnis, A. R., Slane, P. W., Alder, E. M., McMurdo, M.E.T. (2004). Why older people do not participate in leisure time physical activity: A survey of activity levels, beliefs and deterrents. Age and Ageing, 33, 287-292. http://dx.doi.org/10.1093/ageing/afh089

Dahlgren, G., \& Whitehead, M. (2006). Levelling up Part 2: A discussion paper on European strategies for tackeling social inequities in health. Denmark: World Health Organization. Retrieved from http://www.euro.who.int/_data/assets/pdf_file/0018/103824/E89384.pdf

Eriksson, M., \& Lindström, B. (2008). A salutogenic interpretation of the Ottawa Charter. Health Promotion International, 23, 190-199. http://dx.doi.org/10.1093/heapro/dan014

Foster-Fishman, P., Fitzgerald, K., Brandell, C., Nowell, B., Chavis, D., \& Van Egeren, L. (2006). Mobilizing residents for action: The role of small wins and strategic supports. American Journal of Community Psychology, 38, 143-152. http://dx.doi.org/10.1007/s10464-006-9081-0

Hansen-Kyle, L. (2005). A concept analysis of healthy aging. Nursing Forum, 40, 45-57. http://dx.doi.org/10.1111/j.1744-6198.2005.00009.x

Harris, T. J., Carey, I. M., Victor, C. R., Adams, R., \& Cook, D. G. (2008). Optimising recruitment into a study of physical activity in older people: A randomised controlled trial of different approaches. Age and Ageing, 37, 659-665. http://dx.doi.org/10.1093/ageing/afn159

Hartwig, K. A., Bobbitt-Cooke, M., Zaharek, M. M., Nappi, S., Wykoff, R. F., \& Katz, D. L. (2006). The value of microgrants for community based health promotion: Two models for practice and policy. Journal of Public Health Management Practice, 12, 90-96. http://dx.doi.org/10.1097/00124784-200601000-00015

Koelen, M. A., Vaandrager, L., \& Colomer, C. (2001). Health promotion research: Dilemmas and challenges. Journal of Epidemiology and Community Health, 55, 257-262. http://dx.doi.org/10.1136/jech.55.4.257

Krause, N. (2004). Stressors arising in highly valued roles, meaning in life, and the physical health status of older adults. The Journals of Gerontology Series B: Psychological Sciences and Social Sciences, 59, S287-S297. http://dx.doi.org/10.1093/geronb/59.5.S287

Langeland, E., \& Wahl, A. (2009). The impact of social support on mental health service users' sense of coherence: A longitudinal panel survey. International Journal of Nursing Studies, 46, 830-837. http://dx.doi.org/10.1016/j.jnurstu.2008.12.017

Laverack, G. (2009). Public Health. Power, empowerment and professional practice. Hampshire: Palgrave MacMillan.

Lezwijn, J., Vaandrager, L., Naaldenberg, J., Wagemakers, A., Koelen, M. A., \& Van Woerkum, C. M. J. (2011a). Healthy ageing in a salutogenic way: Building the HP 2.0 framework. Health \& Social Care in the Community, 19, 43-51. http://dx.doi.org/10.1111/j.1365-2524.2010.00947.x 
Lezwijn, J., Naaldenberg, J., Vaandrager, L., \& Van Woerkum, C. M. J. (2011b). The interactive use of multi-method and interdisciplinary evidence in the development and implementation of Neighbors Connected. Global Health Promotion, 18, 27-30. http://dx.doi.org/10.1177/1757975910393167

Lindström, B. (2005). Salutogenesis. Journal of Epidemiology and Community Health, 59, 440-442. http://dx.doi.org/10.1136/jech.2005.034777

Lindström, B. (2006). Contextualizing salutogenesis and Antonovsky in public health development. Health Promotion International, 21, 238-244. http://dx.doi.org/10.1093/heapro/dal016

Lindström, B., \& Eriksson, M. (2009). The salutogenic approach to the making of HiAP/healthy public policy: Illustrated by a case study. Global Health Promotion, 16, 17-28. http://dx.doi.org/10.1177/1757975908100747

Lindström, B., \& Eriksson, M. (2010). The Hitchhiker's guide to salutogenesis. Helsinki: Folkhälsan Research Centre, Health Promotion Research, IUHPE Global Working Group on Salutogenesis.

Mohnen, S. M., Groenewegen, P. P., Völker, B., \& Flap, H. (2011). Neighborhood social capital and individual health. Social Science \& Medicine, 72, 660-667. http://dx.doi.org/10.1016/j.socscimed.2010.12.004

Naaldenberg, J., Vaandrager, L., Koelen, M. A., \& Leeuwis, C. (2011). Ageing populations' everyday life perspectives on healthy aging: New insights for policy and strategies at the local level. Applied Gerontology. http://dx.doi.org/10.1177/0733464810397703

Richard, L., Gauvin, L., Gosselin, C., \& Laforest, S. (2009). Staying connected: Neighbourhood correlates of social participation among older adults living in an urban environment in Montreal, Quebec. Health Promotion International, 24, 46-57. http://dx.doi.org/10.1093/heapro/dan039

Rootman, I., Goodstadt, M., Hyndman, B., McQueen, D., Potvin, L., Springett, J. \& Ziglio, E. (eds) (2001). Evaluation in Health Promotion, Principles and Perspectives. WHO Regional Publications European Series, No. 92, Copenhagen.

Schmidt, M., Plochg, T., Harting, J., Klazinga, N. S., \& Stronks, K. (2009). Micro grants as a stimulus for community action in residential health programmes: A case study. Health Promotion International, 24, 234-242. http://dx.doi.org/10.1093/heapro/dap017

Sheldon, S., \& Burke, P. J. (2000). The past, present, and future of an identity theory. Social Psychology Quarterly, 63, 284-297. http://dx.doi.org/10.2307/2695840

Silverman, D. (2006). Interpreting qualitative data. Londen: Sage Publications Ltd.

Suls, J., Martin, R., \& Wheeler, L. (2002). Social comparison: Why, with whom, and with what effect? Current Directions in Psychological Science, 11, 159-163. http://dx.doi.org/10.1111/1467-8721.00191

Tan, E. J., Tanner, E. K., Seeman, T. E., Xue, Q.-L., Rebok, G. W., Frick, K. D., ... Fried, L. P. (2010). Marketing public health through older adult volunteering: Experience corps as a social marketing intervention. American Journal of Public Health, 100, 727-734. http://dx.doi.org/10.2105/AJPH.2009.169151

Utz, R. L., Carr, D., Nesse, R., \& Wortman, C. B. (2002). The effect of widowhood on older adults'social participation. The Gerontologist, 42, 522-533. http://dx.doi.org/10.1093/geront/42.4.522

Wainwright, N. W. J., Surtees, P. G., Welch, A. A., Luben, R. N., Khaw, K.-T., \& Bingham, S. A. (2007). Healthy lifestyle choices: Could sense of coherence aid health promotion? Journal of Epidemiology and Community Health, 61, 871-876. http://dx.doi.org/10.1136/jech.2006.056275

World Health Organization (2002). Active ageing: A policy framework. Geneva, WHO.

\section{(cc) $\mathrm{BY}$}

This work is licensed under a Creative Commons Attribution 3.0 License. 